\title{
Software review
}

\section{Evaluating campaign management or MRM vendors: A business view point}

Received: 11th October, 2006

\section{Shaun Doyle}

is CEO of Cognitive Box, an analytical CRM consulting company. He has been involved in over 200 projects around the world which have been concerned with improving marketing performance through the use of technology. He is currently involved in three projects implementing MRM-type solutions in the UK, USA and Israel. Prior to setting up Cognitive Box, he was founder and chairman of Intrinsic, a campaign management vendor acquired by SAS in March 2001. While at SAS, he was involved in the development of the SAS marketing solutions: Marketing Automation, Marketing Optimisation and Interaction Management.

Shaun Doyle Cognitive Box (Consulting) Ltd Sams Barn

The Greenway West Hendred Wantage, Oxon OX12 8RD, UK Tel: +44 (0)1235821353 Fax: +44 (0)1235 861678 e-mail: shaun.doyle@ cognitivebox.com

Abstract This paper provides a practical guide to the evaluation of campaign management and marketing resource management vendors. It is aimed at senior marketing managers and other marketing users who are going to be part of the evaluation process.

Journal of Database Marketing \& Customer Strategy Management (2006) 14, 78-85. doi:10.1057/palgrave.dbm.3250038

\section{INTRODUCTION}

This paper aims to provide a practical guide for the management of the vendor evaluation process. It is aimed at senior marketing management and other marketing personnel involved in the evaluation of campaign management (CM) and marketing resource management (MRM) vendors. Although focused on CM and MRM, the principles could be applied to any similar project.

This document is based on my experience of being involved in these processes on the client side, as a vendor and as a consultant.

There are a few basic rules that I would like to stress at the start:

- Buyer beware

- Buyer beware

- Buyer beware

This is a process that is fraught with potholes.

\section{DEFINE THE BUSINESS PROBLEM}

When I worked on the vendor side, about 60 per cent of all projects that we were asked to engage in never went anywhere. This means that had we engaged, our competition and the customer would have all wasted time and money.

Before starting the vendor evaluation process, ensure you have a clear understanding of what the marketing problem is that you are trying to resolve. Do not get blinded by the bright light of the technology.

Spend time and document the answer to the following questions.

- What is the marketing problem that I am trying to resolve?

- How do I measure the problem?

- What are the benefits of resolving the problem?

- What are the options to resolving the problem? 
Share with other parties both within marketing and other areas of the business. Validate your understanding of the problem and the potential benefits of resolution.

The following are examples of business problems that marketing teams have used to drive the acquisition of CM and MRM solutions:

- Requirement to significantly increase the volume of campaigns executed;

- Requirement to improve the productivity of the resources in marketing;

- Requirement to improve response rates to customer and prospect communications;

- Requirement to standardise the CM process and remove errors;

- Requirement to monitor and evaluate customer communication activities;

- Requirement to extend the range of customer communication channels available to the business;

- Requirements to replace an existing CM application that is no longer supported as the vendor has gone out of business;

- Requirement to be seen by the market to be proactively addressing the issue of customer management.

Acquiring CM or MRM technology on its own will not solve any of these problems. Recognise from day one that the way you do business will need to change if you are going to realise the expected business benefits. This means that people's roles and responsibilities will change, as will the business processes that they use. Changing these things is a lot harder than buying a piece of software.

\section{SECURE SENIOR MANAGEMENT SUPPORT}

I think that one of the key reasons why so many of these projects do not pass the first step is lack of senior management support.

Once the business problem has been defined and validated with other parts of the business, the next step is to secure senior management support.

A typical CM deployment in a large organisation can cost more than $\mathcal{L}_{100 \mathrm{~K}}$ and, in many cases, with consulting support it can cost millions of pounds.

This means for senior management, failure is a career-threatening decision.

Ensure from day one that the following parties (as a minimum) are in support of the project:

- Marketing Director

- IT Director

- Finance Director

Each has a different set of requirements that you have to show that the project will address.

In the case of the marketing director, he/she will be interested in:

- Impact on marketing performance

- Impact on marketing resource

- How to minimise project risk

- How to realise the business benefits

- Timelines for delivery

- Impact on personal career/agenda

In the case of the IT director, he/she will be interested in:

- Impact on IT resource

- How it fits within current projects

- How will it align to IT strategy

- How to minimise project risk

- Impact on personal career/agenda

In the case of the finance director, he/she will be interested in:

- Financial impact on business

- Benefits realisation plan

- How risk is going to be mitigated

- How project is to be resourced

- Project has support from IT and the business

Each party must understand not only the benefits of problem resolution but what 
resources (people, money, time etc) they will have to commit to the project through its life cycle to ensure success.

This support will need to be secured informally and then formally.

You will need to continue to validate and re-affirm support from senior management at key mile stones during the project.

If you cannot get personal commitment from senior management to do the project, you are doomed to fail.

\section{UNDERSTAND BUSINESS REQUIREMENTS}

The key to success in any procurement process is to understand what you are trying to buy.

The best way to ensure that you understand what you are trying to buy is to document the requirements.

'I don't know about you but I never take a shopping list to the supermarket, as a result I often forget things and buy thing I don't really need'.

In the case of CM or MRM, the following should be documented as a minimum:

- Business requirements

- Functional requirements

- Technical requirements

- Professional services requirements

- Support requirements

\section{Business requirements}

This part of the document should describe in detail what the project is trying to achieve from a business perspective. Example:

1 Increase the number of campaigns executed by the current marketing team (12) from 100 a month to 150 a month within six months of CM been installed.

\section{Functional requirements}

This part of the document should describe in detail what functionality is required of the solution to support the business requirements documented above.

Example:

1 The solution should provide a marketing user with the ability to create campaign reference data

The following types of data will need to be supported by the solution:

- Codes

- Dates eg campaign code

- Numbers eg campaign start date

- Money eg target communication volumes

- Descriptions eg total campaign budget eg campaign objective

\section{Technical requirements}

This part of the document should describe what is required of the solution from a technical perspective. In most cases, this set of requirements will be provided by the IT personnel in the project team.

Example:

1 The CM application will need to support the following database environments either native or through an ODBC driver:

- Oracle Version 9.1

- SQL Server 2003

\section{Professional services requirements}

A significant part of the costs of the delivery of a CM or MRM project will be professional services. (In some cases, it can be $3: 1$; that is, for every pound spent on the software, three pounds is spent on professional services.)

In most of the projects that I now work on, we produce a detailed statement of work for the project as part of the vendor evaluation process. This document defines 
the nature of the professional services support required from the vendor and/or the systems integrator.

As a minimum, the statement of work would cover the following:

- Project structure including phases

- Scope for each phase

- Source systems

- Data

- Customer types

- Functionality

- Communication channels

- Processes to be supported (MRM)

- Project management

- Steering group

- Reporting requirements

- Initial project plan

- Expected profile of the consultants

- Fees and treatment of expenses

\section{Support requirements}

Most vendors focus on the installation of their solution, the reality for the organisation is that it is just the start of the benefits realisation process.

It is important that support requirements are clearly defined as part of the requirements documentation process.

These support requirements should cover:

- Bug resolution

- Software upgrades

- Support service levels

- Input into the vendor product development process

- Publicity and acting as a reference

These requirements should cover both the vendor and the internal IT function where appropriate.

\section{The role of consultants}

In many cases this type of project is the first time that marketing has been involved in defining functional requirements. As a consequence I would strongly recommend that the marketing function seeks support from other parties. These could be:

- Business analysis functions from with IT

- External consultants

- Niche consultants in the CRM arena

- Systems integrators

- Large scale business consultants

The best solution is often a combination of internal and external resource.

Which ever option is selected, always ensure that:

- The number of internal parties involved exceeds the number of external parties involved;

- That none of the key roles are held by external parties;

- You understand the motivation of all the parties involved;

- There is no commercial relationship directly or indirectly with any of the vendors.

There are a number of other sources that can be used to supplement the requirements definition activities. These include:

- Other organisations that have gone through the process

- Vendors and their websites

- Market analysts

- Conferences

With external consultants the same rules apply — buyer beware.

Note: In some cases organisations issue a Request for Information document (RFI) that asks the vendors to provide data that can be used as input into this process. This may include product demonstrations.

\section{DEVELOP BUSINESS CASE}

While the requirements are being documented, start the development of the business case (or ratify the initial business 
case if produced earlier). This should build on any numbers that were created as part of the Problem definition stage. There are very few organisations that will commit significant resource to a project without a solid business case.

It also helps to understand the likely available funds for purchasing software and services. This information can be used to pre-screen some vendors or service providers.

Tip: Involve finance in the process early or otherwise they may undermine what you have done and put the project birth at risk. Get commitment from the CFO that he will resource this process as part of the initial project sell in.

The business case should cover the following as a minimum:

- Problem description

- Proposed problem resolution

- High-level project plan (from inception through benefits realisation)

- Business benefits

- Financials

- Costs

- Benefits

- Investment analysis

- Risk and risk mitigation strategies

- Assumptions

As the tender process moves forward you may need to update the business case.

\section{CREATE THE TENDER DOCUMENT}

At this stage you have senior management support, an approved outline business case and a requirements document.

These will need to be converted to a tender document.

This process should involve internal procurement.

Tip: In most cases procurement would not be involved directly in the development of the requirement document or business case but I would recommend briefing this group early in the process so that they can plan out the appropriate resource.
The procurement team will have a strict set of processes and templates that you will need to apply.

The tender document should include the following:

- Procurement process requirements

- Draft agendas for meetings

- Scenarios to be demonstrated

- Business and technical requirements

- Timetable for evaluation

- Matrix for vendors to complete

- Sample contracts

- Initial project plans

A short list of vendors will need to be agreed and the tender document issued.

Tip: Please ensure you provide adequate time for the vendors to respond appropriately. It will pay off in the long term.

\section{EVALUATE VENDORS}

Once the tender document (often called a request for proposal or RFP) is issued, the vendors will try and qualify the opportunity hard. They will not want to commit the resource without really understanding if it is a real opportunity and that they have a fair chance of winning.

I believe that a well-produced RFP and vendor briefing should provide the required information for them to assess if they should respond. It also cuts down the need for them to bypass the procurement procedure.

The typical vendor evaluation process has the following key steps:

- Organisation issued the RFP

- Vendors respond to RFP

- Organisation short lists 4-5 vendors using scoring matrix

— Vendors present solutions

- Technology

- Delivery capability

- Validate response to tender

- Organisation short lists 2-3 vendors using the scoring matrix 
- Detailed vendor presentation and due diligence

- Detailed product presentations (defined scenarios)

- Proposed technical architecture

- Proposed delivery approach and team

- Reference calls and visits

- Procurement process

- Contract negotiation

- Decision on final vendor

- Proof of concept (optional)

- Project initiation

This process would typically take $12-16$ weeks.

\section{GUIDANCE FOR THE EVALUATION PROCESS}

(Let the games begin)

The following section describes some of the key items that should be managed by the project team:

\section{Quality of response to RFP}

A vendor will try and answer as many possible questions with a yes or fully support. It is important that the vendor answers as accurately as possible for the evaluation to be effective.

\section{Tips:}

- Write all questions as clearly as possible.

- Provide a formal process for the vendor to resolve queries about questions.

- Look for further explanation of how the product supports the requirement.

- Read all responses with care.

\section{Demonstration}

The primary way that a vendor will present their technology is through a demonstration. A vendor will look to present their product in the best possible manner.

\section{Tips:}

- Define the scenarios that the vendors should present.
- Ensure the scenarios cover all the key requirements.

- Get the vendor to present the capabilities in detail.

- Do not ignore application maintenance and management.

- Keep the vendor to pre-defined timelines during the presentation to ensure all functionality is shown.

\section{Intelligence}

The following are typical tactics used by some vendors against procurement procedures:

- Contact members of the project team directly

- Contact sub-ordinates of members of the project team

- Contact senior managers of members of the project team

- Contact consultants supporting the evaluation process

- Contact suppliers for the organisation

The initial focus will be to understand:

- Who the decision makers are

- Who the influencers are

- Who the competition is

- What their perceive strengths and weaknesses are

- What the competitions strengths and weaknesses are

- What tactics the competition is adopting

- If a consultant is involved and, if so, who

Tips:

- Control the flow of all information to the vendors

- Create a single defined line of communication for the vendors.

- Refer all calls from vendors to the nominated individuals.

- Forward all emails received from vendors to the nominated individuals. 
- Report all invitations to informal meetings, for example coffee, drinks, dinner to the nominated individuals

- Do not discuss the project with parties not involved with the evaluation

- Secure copies of all project documentation

- Keep inventory of all documents and who has received what

- Video vendor presentations (keep secure and return after evaluation)

\section{FUD - Fear, uncertainty and doubt}

One way to undermine a competitor is to create:

- Fear

- Uncertainly

- Doubt

So some vendors will leak negative information (sometimes true and sometime not) into the evaluation process either directly during presentations or indirectly through informal channels.

Tips:

— Stop vendors creating FUD during presentations

- Stop vendors from sending documents that create FUD

- Ensure your due diligences process are rigorous

\section{References}

References are seen as an important part of the evaluation process. But it must be recognised that a vendor is only going to list satisfied customers. In some cases, vendors have been known to pay reference organisations directly or indirectly that may sway the results of the reference call or visit.

Tips:

- Use care in selecting a vendor reference

- Try and do the meeting in person - helps with the body language
- Never do a reference call or visit with the vendor present

- Do your own due diligence by calling known customers

- Do a proof of concept (POC) on your site (fully install the technology and deploy test scenarios) - This is resource intensive for all parties but maybe worth it

- Recognise that a failed project may not be due to the vendor

\section{Price}

Although vendors would normally be asked for pricing details as part of the tender, it is very unlikely that this will be the final price.

Tips:

- Ignore price as part of the evaluation in the early stages of the process

\section{CONCLUSION}

Evaluating CM and MRM vendors effectively requires a structured process and tight management of the vendors and the procedures.

The following are the key recommended steps:

- Clearly define the marketing problem that is being resolved

- Secure continued support from senior management for the process

- Document the business, functional and technical requirements in detail

- Create a tight tender document that defines the process and requirement from the vendors

- Manage effectively the detailed vendor evaluation process

I believe that most vendors are trying to do a good job and sell solutions that they believe in. I think the key responsibility lies 
with the buying organisation to ensure that they clearly understand what they need and how the vendor's solution meets those needs.

To achieve this, an organisation should:

- be well prepared

- manage the process well
- not allow a vendor to unduly influence the process

The key to success in any procurement process is to understand what you are trying to buy.

'If you go out to buy a red car, don't come back with a blue bicycle'

(c) Shaun Doyle 